\title{
The Behavior of APO-SUS Rats in Animal Models with Construct Validity for Schizophrenia
}

\author{
B. A. Ellenbroek, ${ }^{1}$ M. A. Geyer, ${ }^{2}$ and A. R. Cools ${ }^{1}$ \\ 'Department of Psychoneuropharmacology, University of Nijmegen, $6500 \mathrm{HB}$ Nijmegen, The Netherlands and \\ 2Department of Psychiatry, University California San Diego, La Jolla, California
}

\begin{abstract}
Schizophrenic patients are known to suffer from a number of information processing disturbances, including deficits in both prepulse inhibition of startle and latent inhibition. Since these behavioral phenomena can also be observed in animals, they represent an ideal starting point for developing animal models having construct validity for specific deficits observed in schizophrenia. The principal question is how to induce a condition in animals most similar to the schizophrenic deficit. In the present study, we have selected rats on the basis of their response to an open field or to the dopaminergic agonist apomorphine, and evaluated their prepulse inhibition and latent inhibition. We used three different selection procedures (open field selection for novelty response, gnawing cage selection for apomorphine response, and pharmacogenetic selection for apomorphine response).

The results show that, irrespective of the selection procedure used, rats with a high response to novelty or apomorphine susceptible (collectively called APO-SUS rats) show diminished prepulse inhibition of the acoustic startle response as compared to rats with a low response to novelty or apomorphine unsusceptible (collectively called APO-UNSUS rats). This difference was apparent only at low prepulse intensities. Moreover, these APO-SUS rats show diminished latent inhibition in a conditioned taste aversion paradigm as compared to APO-UNSUS rats. Given the fact that the pharmacogenetically bred APO-SUS rats show several central nervous, endocrinological, and immunological similarities to schizophrenic patients, they are hypothesised to represent an interesting nonpharmacological animal model for schizophrenia-prone patients.
\end{abstract}

[Key words: schizophrenia, APO-SUS rats, animal model, prepulse inhibition, latent inhibition, acoustic startle response]

Research into the neurobiological deficits involved in schizophrenia has long heen hampered by a lack of adequate animal models for this severe psychiatric disorder. Thus, most animal models have not established more than predictive validity (El-

Received Apr. 10, 1995; revised July' 14, 1995; accepted July 19, 1995.

We express our gratitude to Mr. L. Lubbers and Mr. M. Frenken for their valuable help in performing the experiments. M. A. Geyer was supported by a National Institute of Mental Health Research Scientist Award (KO5MH01223) and a Fogarty Senior International Fellowship (F6TW01813).

Correspondence should be addressed to B. A. Ellenbroek, Department of Psychoneuropharmacology, University of Nijmegen, P.O. Box 9101, $6500 \mathrm{HB}$ Nijmegen, the Netherlands.

Copyright (C) 1995 Society for Neuroscience 0270-6474/95/157604-08\$05.00/0 lenbroek, 1993), which limits their ability to enhance our understanding of schizophrenia. The development of animal models has, however, gained momentum in the last number of years, due to the results of neuropsychological and psychophysiological research showing information processing deficits in schizophrenic patients (Braff, 1993). Thus, schizophrenic patients show, among others, deficits in prepulse inhibition of the acoustic startle response and in latent inhibition. Prepulse inhibition refers to the diminished response to an acoustic startle stimulus when it preceded by a less intense acoustic stimulus. Latent inhibition refers to the detrimental effect of prior stimulus preexposure to the subsequent condition of that specific stimulus. In comparison to control subjects, schizophrenic patients are known to have decreased prepulse inhibition (Braff and Geyer, 1990) and diminished latent inhibition (Baruch et al., 1988). The advantage of these paradigms is that they can be measured with almost identical methods in humans and rats, making them suitable for studying the neuronal substrates of information processing deficits observed in schizophrenic patients. Indeed, these paradigms represent important examples of animal models with construct validity for specific deficits observed in schizophrenia (Ellenbroek and Cools, 1990; Geyer and Markou, 1995), for instance, models in which the psychopathological construct of the disease is modeled (Willner, 1984).

Nevertheless, an important question in relation to schizophrenia is how to induce a "schizophrenia-like" condition. So far, research has focussed predominantly on the dopamine hypothesis. Thus, the indirect dopamine agonist amphetamine is known to induce deficits in prepulse inhibition (Mansbach et al., 1988) and latent inhibition (Weiner et al., 1984). In this respect, one could argue that the usefulness of these models is not much higher than that of animal models with predictive validity (Ellenbroek, 1993). An alternative strategy may be to search for differences among rat lines or strains (Glowa and Hansen, 1994). Thus, the Maudsley Low reactive rats (Commissaris et al., 1988) and the Flinders resistant rats show startle habituation deficits (Markou et al., 1993). As yet, however, no strain of rats has been found to show deficits in prepulse inhibition or latent inhibition. A number of years ago we started to breed Wistar rats selected on their stereotyped gnawing response to apomorphine (Cools et al., 1990). These rats (the apo-morphine susceptible APO-SUS and unsusceptible APO-UNSUS lines) not only show a differential response to apomorphine, but also differ in a large number of behavioral, endocrinological, and immunological parameters (Cools et al., 1990, 1993, 1994). Interestingly, the APO-SUS rats show a heightened response to external stimuli, which is reminiscent of schizophrenic patients (McGhie, 1970). 
This observation led us to suggest that the APO-SUS rats might also show deficits in information processing reminiscent of schizophrenia. In order to investigate this hypothesis, we used animals selected from our normal outbred Wistar colony, as well as animals from our pharmacogenetically bred lines and tested them in two experimental paradigms: prepulse inhibition of the acoustic startle response and latent inhibition with the conditioned taste aversion paradigm.

\section{Materials and Methods}

The experiments were performed in accordance with the Helsinki Declaration and institutional guidelines.

\section{Animals and selection procedure}

All Wistar rats were obtained and bred in the Central Animal Laboratory of the Univ of Nijmegen. They weighed between 200 and $250 \mathrm{gm}$ at the time of the experiment and had water and food freely available except during the experiment. They were housed in temperature-controlled rooms with a standard 12 L:12 D cycle: lights on from 0700 to $1900 \mathrm{hr}$. Three different types of selection procedures were used (Cools et al., 1990):

(I) Open-field selection. For this selection procedure, drug and experiment naive male Wistar rats were obtained from our normal outbred strain. Three days before the selection procedure they were individually housed in MacrolonR cages $(40 \times 25 \mathrm{~cm})$. At the day of the experiment each rat was placed in the experimental room $30 \mathrm{~min}$ before testing to adapt to the environment. After this period the rat was placed on a large open field $(160 \times 160 \mathrm{~cm})$ without walls. The behavior of the rat was recorded for $30 \mathrm{~min}$ with the help of a videotracking system developed in our laboratory. This system allows the continuous recording of locomotor behavior and gives information on (among others) habituation time (defined as the time until the rat stops for at least $90 \mathrm{sec}$ ), total locomotor activity as well as locomotor patterns. Previously, we have shown that this procedurc allows for the discrimination between high responders (HR) and low responders (HR) to novelty (Cools et al., 1990). HR rats are defined as animals that locomote more than 6000 $\mathrm{cm}$ and habituated in more than $840 \mathrm{sec}$. LR rats are defined as animals that locomote less than $4800 \mathrm{~cm}$ and habituate in less than $480 \mathrm{sec}$. In the past we have shown that the behavior in this open field closely correlates with apomorphine susceptibility (Cools et al., 1990). More specifically, HR show a high susceptibility to apomorphine, whereas LR show a low susceptibility to apomorphine.

(2) Gnawing cage selection. For this selection procedure, male Wistar rats were obtained from our normal outbred population. The animals received subcutaneous injections of $1.5 \mathrm{mg} / \mathrm{kg}$ apomorphine $\mathrm{HCl}$ (Brocades ACF) in the neck and immediately placed in the gnawing box for $45 \mathrm{~min}$. This box is virtually identical to that of Ljungberg and Ungerstedt (1978). It consists out of a perspex hole board $(69 \times 69$ $\mathrm{cm})$ with a central cubicle $(25 \times 25 \mathrm{~cm})$. The box contains 32 holes, each of which is surrounded by 10 concentric ridges. A microphone is placed underneath the central cubicle to allow registration of sounds. Through this microphone and a large number of infrared breams, a number of behavioral activities can be automatically recorded, like locomotor activity, frequency, and duration of hole dipping, etc. For our purpose, only the stereotyped gnawing response is important. The gnawing on the ridges surrounding the holes produces a characteristic sound that is detected by the microphone, fed into the computer, and scored as one gnaw. Based on this gnawing response, we have selected two types of rats: GNAW rats, i.e., rats that gnaw more than 500 times per $45 \mathrm{~min}$ and NONGNAW rats, i.e., rats with gnaw less than 10 times per $45 \mathrm{~min}$. Half of the animals were subjected to the gnawing test 1 week before being placed in the prepulse inhibition or the latent inhibition paradigm and the other half 1 week after the prepulse inhibition. Since there were no statistically significant differences in either prepulse inhibition scores or in gnawing scores, the results of both groups were added together.

(3) Pharmacogenetic selection. As discussed in the introductory paragraphs, several years ago we started a breeding program to pharmacogenetically select apomorphine susceptible and unsusceptible rats (Cools et al., 1990). After an initial selection in the gnawing box (described above), the nine males and females with the highest score and the nine males and females with the lowest score were paired (the F0 generation). Their offspring was again tested in the gnawing box and for each new generation, the four best male and female litters were selected. The best litters are defined as those litters showing the highest (APO-SUS) and the lowest (APO-UNSUS) mean gnawing response per gender. Out of these four best male and female litters nine new pairs of rats were selected to produce the next generation, with the condition that brother/sister pairing is not allowed. The litters are weaned $28 \mathrm{~d}$ after birth. After weaning, the fathers are returned to the mothers to allow for two more litters to be made. These litters are being used for other experiments (such as the ones described in this article). The present experiments were performed with naive male APO-SUS and APOUNSUS rats belonging to the 17 th and 18th generation. APO-SUS rats are defined as animals born from an APO-SUS mother and father. APOUNSUS rats are likewise defined as animals born from an APO-UNSUS father and mother. The animals were individually housed $3 \mathrm{~d}$ before the experiments in macrolon cages $(40 \times 25 \mathrm{~cm})$ with food and water ad libitum.

\section{Prepulse inhibition of the acoustic startle response}

The prepulse inhibition experiments were performed in a acoustic startle chamber of San Diego Instruments. Basically, the cage consists of a Plexiglas tube $(8.2 \mathrm{~cm}$ in diameter, $25 \mathrm{~cm}$ in length) resting on a plastic frame. A piezoelectric accelerometer mounted under the tube detected and transduced the motion of the tube. Stimulus delivery was done using the SR-LAB software, via a speaker mounted $10 \mathrm{~cm}$ above the cylinder. The computer software also digitized, rectified, and recorded the response of the accelerometer, with $1001 \mathrm{msec}$ readings collected beginning at stimulus onset. Startle amplitude was defined as the average of the 100 readings. The whole system was mounted within a sound attenuating chamber. Throughout the startle session a background level of $70 \mathrm{~dB}$ was maintained.

The startle session started with a 5 min habituation session in the startle system. After this habituation period, five startle pulses (120 $\mathrm{dB}\lceil\mathrm{A}], 40 \mathrm{msec}$ broad band burst, the A refers to the A weighing scale for sound measurement) were delivered to test basal startle responsiveness. Next, five blocks of seven trials were delivered to measure prepulse inhibition. Each of these blocks consisted of two startle trials, one no-stimulus condition and one of four different prepulse-startle pairing administered pseudorandomly. In these pairings the prepulse was either $2,4,8$, or $16 \mathrm{~dB}[\mathrm{~A}]$ above background. These prepulses were always $20 \mathrm{msec}$ broad band bursts and were always followed by a startle pulse (120 dB[A]) $100 \mathrm{msec}$ later. The session was terminated by five additional startle pulses to allow a measure for startle habituation. The interval between two trials was between 10 and $20 \mathrm{sec}$.

The degree of prepulse inhibition (in percentage) was calculated according to the formula

$$
100-\frac{\text { startle amplitude on prepulse trial }}{\text { startle amplitude on startle trial }} \times 100 .
$$

\section{Latent inhibition}

Latent inhibition was measured using the conditioned taste aversion paradigm. Rats were housed individually. Food was freely available throughout the experiment. Water bottles were removed from their cages $24 \mathrm{hr}$ before the start of the experiment. On the first day of the experiment rats were subdivided into two groups: a preexposed group and a nonpreexposed group. The whole experiment was performed in the home cage of the rats. The preexposed group received a bottle with 50 $\mathrm{ml}$ of a $5 \%$ sucrose solution, whereas the nonpreexposed group received a bottle with $50 \mathrm{ml}$ of plain tap water for $30 \mathrm{~min}$. After these $30 \mathrm{~min}$, the bottles were weighed to determine the amount of solution drunk. This procedure was repeated at day 2 and 3 . At day 4 , all rats were given a bottle of $50 \mathrm{ml}$ of a $5 \%$ sucrose solution, again for $30 \mathrm{~min}$. Immediately after the $30 \mathrm{~min}$ each rat was treated with $50 \mathrm{mg} / \mathrm{kg}$ of $\mathrm{LiCl}(5 \mathrm{ml} / \mathrm{kg}$ i.p). On the final test day (day 5 ) the rats received one bottle with $50 \mathrm{ml}$ of tap water and one bottle with $50 \mathrm{ml}$ of $5 \%$ sucrose. The degree of conditioned taste aversion (in \%) is determined by the formula

$$
\frac{\mathrm{ml} \text { of sucrose consumed }}{\mathrm{ml} \text { of sucrose consumed }+\mathrm{ml} \text { of tap water consumed }} \times 100 \text {. }
$$

In the series of experiments with the APO-SUS and APO-UNSUS rats, an additional experiment was performed with $1 \mathrm{~d}$ preexposure. In this case, all rats (preexposed and nonpreexposed) received $50 \mathrm{ml}$ of tap water at days 1 and 2 for $30 \mathrm{~min}$. Only at day 3 the preexposed 


\section{PREPULSE INHIBITION \\ Open Field Selection}

Figure I. The effects of different prepulse intensities on the acoustic startle response of animals selected on the open field. The percentage of inhibition $( \pm$ SEM) is calculated as described in the Materials and Methods section. ${ }^{*} p$ $<0.05$ one-way ANOVA HR versus LR rats.

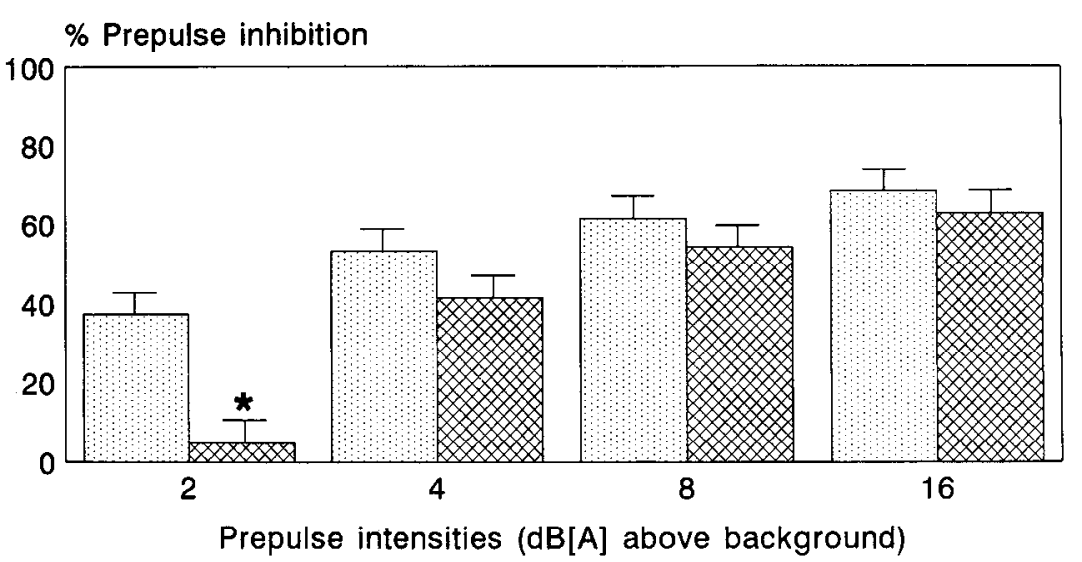

Prepulse intensities (dB[A] above background) group received $50 \mathrm{ml} 5 \%$ sucrose, whereas the nonpreexposed group again received tap water. Days 4 and 5 were identical to the procedure just described. This experiment was added because $3 \mathrm{~d}$ preexposure gave a strong latent inhibition effect, which might mask the subtle differences between APO-SUS and APO-UNSUS.

\section{Statistics}

In the prepulse inhibition experiment a mixed ANOVA was used with the different prepulse intensities as within-subject factors and the groups of rats as between-subject factors. In case of statistical differences between the two groups of rats, one-way ANOVA was used to analyze the difference between the groups for each prepulse intensity. In the latent inhibition experiment, a two-way ANOVA was performed with factors preexposure and rat group. All $p$-values mentioned are two tailed.

\section{Results}

\section{Prepulse inhibition}

Three prepulse inhibition experiments were performed with rats of each of the three selection procedures. For sake of clarity, we will discuss each of these separately.

\section{$H R$ and $L R$ rats}

The high- and low responders to novelty selection was done on 20 male Wistar rats. Six rats fulfilled the criteria for LR (mean distance $3711 \pm 343 \mathrm{~cm}$, mean habituation time $392 \pm 87 \mathrm{sec}$ ) and six fulfilled the criteria for HR (mean distance $8456 \pm 496$ $\mathrm{cm}$, mean habituation time $1273 \pm 380 \mathrm{sec}$ ).

The prepulse inhibition response of the HR and LR rats is displayed in Figure 1. There were no differences in basal startle reactivity, as measured by the first five startle responses (see Materials and Methods): HR, $789 \pm 103$; LR, $685 \pm 78$. However, there were differences in prepulse inhibition. The mixed ANOVA showed an overall significant effect as well as a significance interaction between group and prepulse condition $[F(4,54)=4.6, p<0.05]$. One-way ANOVA showed that HR had significantly less prepulse inhibition at the lowest prepulse intensity ( $2 \mathrm{~dB}[\mathrm{~A}]$ above background) $[F(1,58)=4.71, p<$ $0.05]$. There were no significant differences between groups at other prepulse intensities.

\section{NONGNAW and GNAW rats}

As described in the Materials and Methods section, two groups of 20 rats were tested. Group 1 was tested in the gnawing box 1 week before the prepulse inhibition session; the other group first received a prepulse inhibition session followed, 1 week later, by a gnawing box experiment. Since there were no statistically significant differences between the two groups on either test, the data were pooled. Out of these 40 rats tested, 10 fulfilled the criteria for nongnawing rats (mean gnawing score of $2.4 \pm$ 2.7 ) and 13 fulfilled the criteria for gnawing rats (mean gnawing score $1022 \pm 417$ ).

The prepulse inhibition response of the NONGNAW and GNAW rats is displayed in Figure 2. Again, there were no differences in basal startle reactivity, as measured by the first five startle responses: NONGNAW rats, $471 \pm 30$; GNAW Rats, 544 \pm 30 . However, there were differences in prepulse inhibition. The mixed ANOVA showed an overall significant effect as well as a significant interaction between group and prepulse condition $[F(4,109)=2.83, p<0.05]$. As in the case of the open-field selection, the difference observed between the groups selected in the gnawing box could be ascribed to a significant difference at the lowest prepulse intensities [one-way ANOVA, $F(1,113)$ $=2.94, p<0.05]$. There were, again, no significant differences between groups at other prepulse intensities.

\section{APO-UNSUS and APO-SUS rats}

For this experiment, 10 male APO-UNSUS and 9 male APOSUS rats were used. In contrast to the open-field and the gnawing box selection, these pharmacogenetically selected animals differed in basal startle reactivity: APO-SUS mean $1444 \pm 161$; APO-UNSUS mean $883 \pm 107$. This difference was highly significant $[F(1,93)=10.16, p<0.002]$.

Moreover, these animals differed in the degree of prepulse inhibition. As can be seen from Figure 3, there was a significant prepulse condition with group interaction $[F(4,89)=3.12, p<$ $0.05)$. One-way ANOVA showed that this was due to differences between the groups at both the $2 \mathrm{~dB}[\mathrm{~A}]$ prepulse trials $[F(1,93)$ 


\section{PREPULSE INHIBITION}

\section{Gnawing Box Selection}

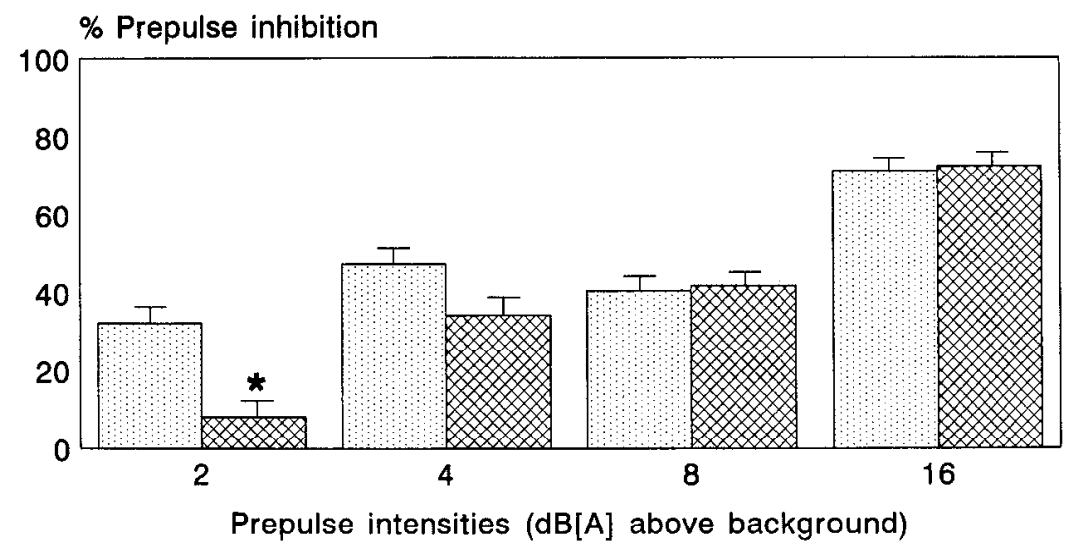

DNONGNAW 网GNAW

Figure 2. The effects of different prepulse intensities on the acoustic startle response of animals selected in the gnawing box. The percentage of inhibition ( \pm SEM) is calculated as described in the Materials and Methods section. ${ }^{*} p<0.05$ one-way ANOVA GNAW versus NONGNAW rats.
$=5.22, p<0.05]$ and the $4 \mathrm{~dB}[\mathrm{~A}]$ prepulse trials $[F(1,93)=$ $3.79, p<0.05]$.

\section{Latent inhibition}

NONGNAW and GNAW rats. For this experiment, 50 rats were subdivided into two groups of 25 . One group was first tested in the gnawing box with apomorphine, followed 1 week later by the latent inhibition paradigm. The reverse order was used for the second group. Since no siginificant differences was seen on either the latent inhibition or the gnawing box scores, the data were pooled.

The 50 rats were subdivided into one preexposure group and one nonpreexposure group in the latent inhibition paradigm. The results of this experiment are displayed in Figure 4. There were no differences in overall intake of water and sucrose of the test day (nonpreexposed group $11.8 \pm 1.8 \mathrm{ml}$; preexposed $13.2 \pm$ $1.0 \mathrm{ml}$ ). However, there were clear differences between the two groups with respect to sucrose preference. The rats receiving 3 $\mathrm{d}$ of water prior to the conditioning trial (the nonpreexposed group) showed a strong conditioned taste aversion, as is seen by the very low sucrose preference $(20.1 \pm 2.4 \%)$. On the other hand, the animals that received $3 \mathrm{~d}$ of preexposure of $5 \%$ sucrose solution show a much smaller degree of conditioned taste aversion as is shown by the much higher sucrose consumption. In other words, prior preexposure reduced conditioning, for instance, latent inhibition had occurred.

When the percentage of sucrose consumption on the test day was plotted as a function of the apomorphine induced gnawing score an interesting picture occurred (Fig. $4 b$ ). Although there was no relationship for the nonpreexposed group (data not

\section{PREPULSE INHIBITION \\ Pharmacogenetic Selection}

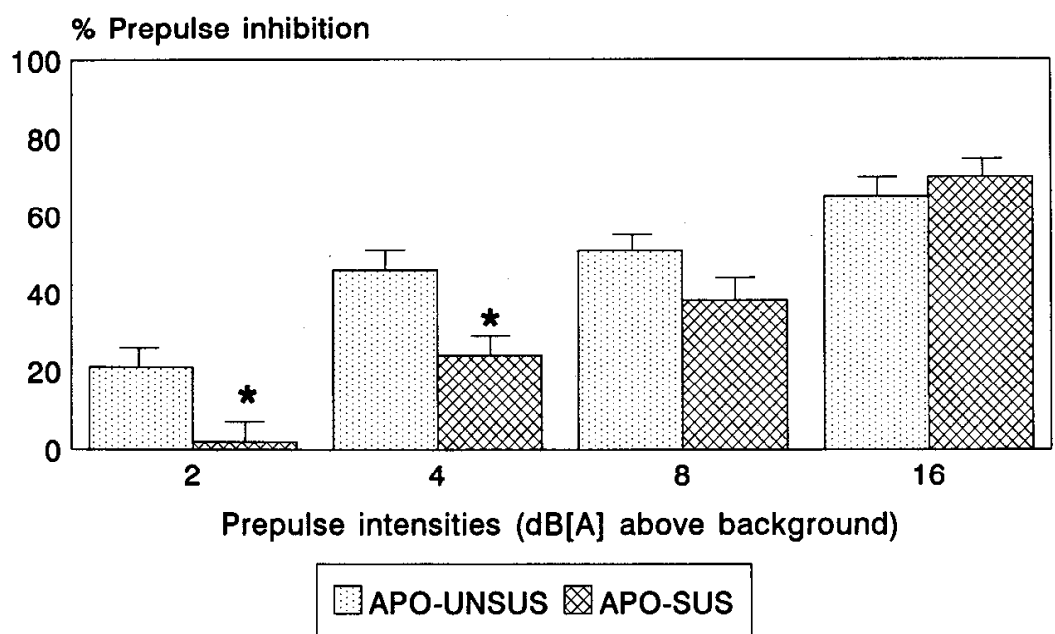

Figure 3. The effects of different prepulse intensities on the acoustic startle response of animals selected from the pharmacogenetic breeding program. The percentage of inhibition ( \pm SEM) is calculated as described in the Materials and Methods section. ${ }^{*} p<0.05$ one-way ANOVA APO-SUS versus APO-UNSUS rats. 

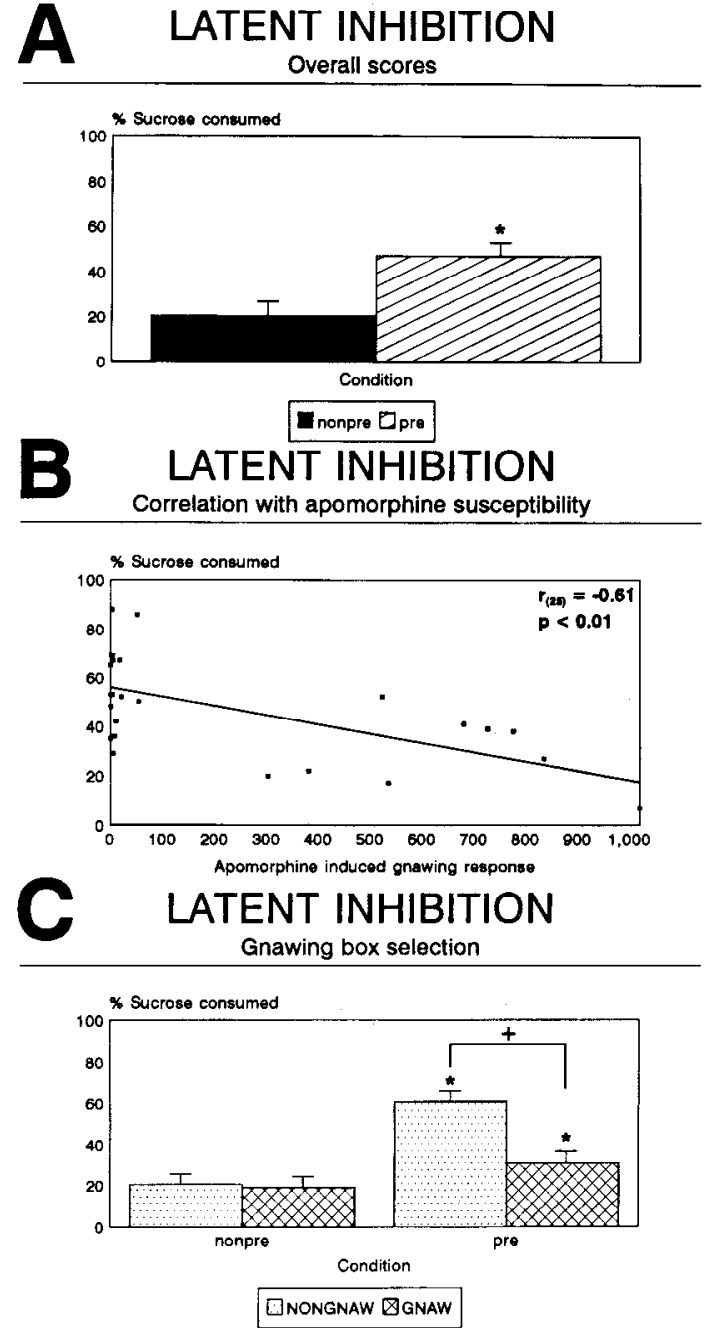

Figure 4. A, The effects of $3 \mathrm{~d}$ of preexposure on the percentage sucrose consumed $( \pm$ SEM) at the test day, $24 \mathrm{hr}$ after a single injection of $50 \mathrm{mg} / \mathrm{kg} \mathrm{LiCl}$ (i.p.) in the conditioned taste aversion paradigm. ${ }^{*} p$ $<0.05$ preexposure versus nonpreexposure. $B$, Correlation between the percentage of sucrose consumed at the test day the response to apomorphine. $C$, The effects of $3 \mathrm{~d}$ of preexposure on the percentage sucrose consumed ( \pm SEM) at the test day for rats selected in the gnawing box. ${ }^{*} p<0.05$ preexposure versus nonpreexposure (post hoc Duncan); $+p<0.05$ NAW versus NONGNAW rats (post hoc Duncan).

shown), there was a significant negative correlation between apomorphine induced gnawing and percentage of sucrose consumed $[r(25)=-0.62 ; p<0.01]$. In other words, the animals with the highest apomorphine gnawing score had the least latent inhibition. This can also be seen in Figure $4 c$. Subdividing the animals according to the criteria described in the Materials and Methods section leads to 10 NONGNAW rats (mean gnawing score $3.0 \pm 0.8$ ) and 8 GNAW rats (mean gnawing score 728 \pm 65 ). These animals show a significant difference in degree of latent inhibition $[F(1,16)=19.08, p<0.0005]$.

APO-UNSUS and APO-SUS rats. For this experiment 18 rats belonging to the APO-UNSUS selection line and 18 belonging to the APO-SUS selection line were used. These rats were stit divided into six groups of six rats. One group of each line received $0 \mathrm{~d}$ of preexposure, one group of each line received $1 \mathrm{~d}$ of preexposure, and one group of each line received $3 \mathrm{~d}$ of preexposure to the 5\% sucrose solution. One APO-SUS rat belonging to the $0 \mathrm{~d}$ preexposure had to be discarded because of leakage of the bottle. Although APO-SUS rats comsumed a little more sucrose during the $3 \mathrm{~d}$ preexposure than APO-UNSUS rats, this did not reach significance (APO-SUS $13.6 \pm 1.2 \mathrm{ml}$; APOUNSUS $11.9 \pm 1.1 \mathrm{ml}$ ). The results of the final test day are displayed in Figure 5. ANOVA showed a highly significant effect of preexposure $[F(2,31)=28.37, p<0.001]$ and rat type $[F(1,32)=9.3, p<0.005]$. The interaction between preexposure and rat type was not siginificant $[F(2,31)=2.12, p>0.13]$. Post hoc Duncan tests showed that APO-SUS rats showed less latent inhibition (i.c., drank less sucrose) both at $1 \mathrm{~d}$ and at $3 \mathrm{~d}$ preexposure. Moreover, whereas the APO-UNSUS showed a significant degree of latent inhibition already at $1 \mathrm{~d}$ preexposure, the APO-SUS rats did not.

\section{Discussion}

Animal models with construct validity for schizophrenia are generally based on information processing deficits (Ellenbroek and Cools, 1990). However, an important problem is that we do not know how these processes can be disturbed in a way resembling schizophrenia. In the present study, we have analyzed two information processing aspects in rats selected on the basis of their apomorphine response or their response to novelty. In the past, we have shown that these selection paradigms lead to very similar groups of rats (Cools et al., 1990). The present data also show that animals with a high susceptibility for apomorphineinduced gnawing or a high response to novelty have a strongly reduced prepulse inhibition and a strongly diminished latent inhibition. Indeed, the data are almost identical for all three groups of rats. Nevertheless, there are some differences. Thus, whereas the HR and GNAW rats show diminished prepulse inhibition only at $2 \mathrm{~dB}[\mathrm{~A}]$ prepulse intensity, the APO-SUS rats showed disruption at 2 and $4 \mathrm{~dB}[\mathrm{~A}]$. Likewise, whereas the GNAW rats showed diminished latent inhibition with a $3 \mathrm{~d}$ preexposure time, the APO-SUS rats a diminished latent inhibition at both 1 and $3 \mathrm{~d}$ preexposure. Taking these data together, it appears that the difference between APO-SUS and APO-UNSUS rats is larger than between HR and LR rats or between GNAW and NONGNAW rats. This result is not surprising, given the fact that APOSUS and APO-UNSUS rats have been bred for 17 generations. During the course of this breeding scheme, the mean differences in apomorphine-induced gnawing also continuously increased (Cools et al., 1990; Ellenbroek and Cools, unpublished data).

Apart from these differences in degree of prepulse and latent inhibition, there were also differences in baseline startle amplitude. Thus, APO-SUS rats had a much higher baseline startle response $(1444 \pm 161)$ than the other two rat types [ANOVA $F(2,137)=6.37, p<0.002$; post hoc Duncan $p<0.05 \mathrm{APO}$ SUS larger than both HR and GNAW rats]. No such differences were found between LR, NONGNAW, and APO-UNSUS rats [ANOVA $F(2,127)=2.68, p>0.05$ ]. It is at present difficult to explain this difference in baseline startle amplitude. There are indications that enhanced arousal leads to increases in baseline startle amplitude (Servatius et al., 1994) that would be in agreement with the heightened ACTH and corticosterone levels in APO-SUS rats upon novelty stress (Rots et al., 1993).

\section{Prepulse inhibition}

Irrespective of the selection procedure, APO-SUS, HR, and GNAW rats showed diminished prepulse inhibition and latent inhibition. With respect to the neuronal mechanisms underlying prepulse inhibition, or the disruption thereof, most studies have focussed on the dopaminergic activity in the nucleus accumbens. 


\section{LATENT INHIBITION}

\section{Pharmacogenetic selection}

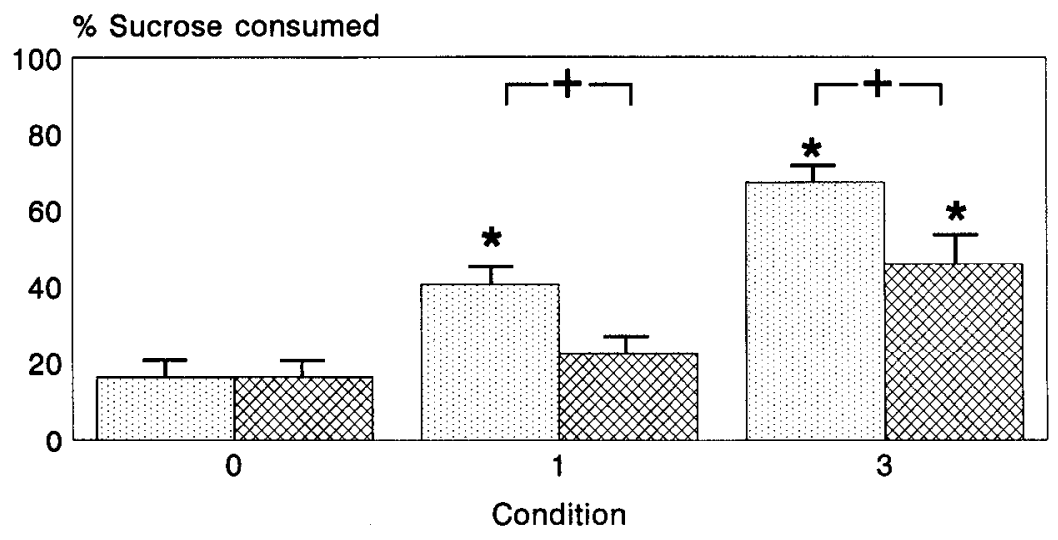

APO-UNSUS APO-SUS

Figure 5. The effects of 0,1 , and $3 \mathrm{~d}$ preexposure on the percentage sucrose consumed ( \pm SEM) at the test day, 24 $\mathrm{hr}$ after a single injection of $50 \mathrm{mg} / \mathrm{kg}$ $\mathrm{LiCl}$ (i.p.) in the conditioned taste aversion paradigm. ${ }^{*} p<0.05$ preexposure versus nonpreexposure (post hoc Duncan); $+p<0.05$ APO-SUS versus APO-UNSUS (post hoc Duncan).
Thus, local infusion of dopamine (Swerdlow et al., 1990) or the dopamine $D_{2 / 3}$ agonist quinpirole (Wan et al., 1994) into the nucleus accumbens disrupts prepulse inhibition. Moreover, early social isolation (at weaning), which is accompanied by an increase in mesolimbic dopamine, reduces prepulse inhibition (Geyer et al., 1993). From these data one would expect an increase in dopaminergic (especially $\mathrm{D}_{2}$ ) transmission in APOSUS rats, given their diminished sensorimotor gating. However, although we have not yet measured the dopamine content or transmission in these animals, behavioral data suggest a low functional dopamine $D_{2}$ activity in the nucleus accumbens of APO-SUS rats (Cools et al., 1994), which would also explain their increased sensitivity to apomorphine. A possible explanation for this apparent conflict is provided by a recent study of Schwarzkopf and his colleagues (1992). They showed that rats, neonatally treated with 6-OHDA, showed disrupted prepulse inhibition, despite a virtually complete loss $(>90 \%)$ of dopamine in the dorsal striatum. These authors suggested that these animals are characterized by a low "tonic" level of dopamine, but an enhanced responsiveness of the dopaminergic system. Interestingly, APO-SUS rats are also characterised by an increased responsiveness of both the hypothalamus-pituitary-adrenal axis and the dopaminergic system (Cools et al., 1994; Rots et al., 1995). Moreover, neonatally 6-OHDA lesioned rats (Schwarzkopf et al., 1992) and APO-SUS rats (Cools et al., 1994) have increased $\mathrm{D}_{2}$ dopamine receptor binding in the dorsal striatum. In other words, the reduced prepulse inhibition of these animals may have been due to an enhanced "phasic" release of dopamine in response to startle testing.

\section{Latent inhibition}

Latent inhibition refers to the detrimental effect of prior stimulus preexposure upon the subsequent conditioning of that stimulus. Schizophrenic patients, in an acute stage of their illness, have a reduced latent inhibition (Baruch et al., 1989). Gray et al. (1992) have proposed that the reduced latent inhibition of schizophrenic patients is due to their decreased ability to use previously stored information. As with prepulse inhibition, we found that GNAW rats and APO-SUS rats have reduced latent inhibition. Given the fact that HR and APO-SUS rats behaved virtually identical to each other (cf Cools et al., 1990), we did not test HR rats. Moreover, we could show that there was an inverse relationship between degree of latent inhibition and apomorphine gnawing response (Fig. $4 b$ ).

There is ample evidence for a role of dopamine in the mediation of latent inhibition. Thus, amphetamine reduces latent inhibition when given in both the preexposure and the conditioning phase (Weiner et al., 1984; Gray et al., 1992; Killcross and Robbins, 1993). In spite of the clear evidence for a role of dopamine in latent inhibition, the neuronal mechanisms underlying this phenomenon are still very unclear. Solomon and Statton (1982) have presented evidence that local application of dopamine into the nucleus accumbens but not the dorsal striatum disrupts latent inhibition. However, this could not be replicated by Killcross and Robbins (1993). Moreover, early social isolation, which leads to an increase in dopamine transmission within the ventral striatum, does not affect latent inhibition (Wilkinson et al., 1994). On the other hand, early maternal separation, which affects the dopaminergic transmission within the dorsal striatum and which enhances the sensitivity for apomorphine, also reduces latent inhibition (Ellenbroek and Cools, 1995).

\section{APO-SUS rats as a model for schizophrenia-prone patients}

Overall, the results of the present study suggest that APO-SUS rats resemble schizophrenic patients in at least two paradigms: latent inhibition, i.e., a cognitive deficit characteristic of acute schizophrenia, and prepulse inhibition, i.e., a psychophysiological deficit that seems to occur both in treated and nontreated schizophrenic. These data suggest that the APO-SUS rats may represent an interesting animal model for at least certain information processing aspects of schizophrenia. However, disturbances in prepulse inhibition does not only occur in schizophrenic patients, but also in schizotypal patients (Cadenhead et al., 1993) and in patients suffering from obsessive compulsive disorders (Swerdlow et al., 1993). Less is known about the specificity of latent inhibition, although disturbances have been reported in psychotic-prone subjects (DeLaCasa et al., 1993). In other words, it is not yet clear how well APO-SUS rats model 
the schizophrenic condition specifically. One difference between schizophrenic patients and APO-SUS rats is related to the prepulse intensity effect. Thus, whereas APO-SUS rats only show disruption of prepulse inhibition with low intensity prepulses (Fig. 3), schizophrenic patients have disturbances at all intensities tested (Grillon et al., 1992). It is at present unclear whether this represents a qualitative difference (i.e., different mechanisms acting at different prepulse intensities), or a quantitative difference (i.e., with increasing prepulse intensities the differences between APO-SUS and UNSUS is reduced). There is, however, some evidence for the latter explanation. Thus, the pharmacogenetically selected APO-SUS show deficits at 2 and $4 \mathrm{~dB}[\mathrm{~A}]$ prepulse intensity, whereas the animals selected with the gnawing cage only show deficits at $2 \mathrm{~dB}[\mathrm{~A}]$. Moreover, we have recently shown that the dopaminergic agonist 7-OHDPAI disrupts prepulse inhibition in a dose-dependent manner (Ellenbroek and Cools, in preparation): $0.1 \mathrm{mg} / \mathrm{kg}$ only affects $2 \mathrm{~dB}$ [A], $0.33 \mathrm{mg} / \mathrm{kg}$ affects 2 and $4 \mathrm{~dB}[\mathrm{~A}]$, and $1 \mathrm{mg} / \mathrm{kg}$ affects 2 , 4 , and $8 \mathrm{~dB}[\mathrm{~A}]$. If the difference is, indeed, of a quantitative nature, it seems logical to assume that further breeding should eventually lead to disruption of prepulse inhibition at all prepulse intensities.

The validity of APO-SUS rats as animal models for (aspects of) schizophrenic patients can also be studied in other paradigns like P50 gating, startle habituation, Kamin Blocking. This is currently under investigation. However, APO-SUS rats show more similarities with schizophrenia. Thus, APO-SUS rats (Cools et al., 1994) and schizophrenic patients (Toru et al., 1984) have elevated level of mRNA for tyrosine hydroxylase in the substantia nigra pars compacta. Likewise, enhanced metabolism in the globus pallidus has been described in schizophrenic patients (Early et al., 1987) and in APO-SUS rats (Cools et al., 1994). APO-SUS rats have also been found to have enhanced levels of dopamine $\mathrm{D}_{2}$ binding in the dorsal striatum (Cools et al., 1994). Whether increased binding of $\mathrm{D}_{2}$ antagonist also occur in the caudate-putamen of drug naive schizophrenic patients remains unclear. Thus Wong et al. (1986) did report increases, which could, however, not be replicated in at least two other studies (Farde et al., 1990; Martinot et al., 1990). It has been hypothesized for a long time that schizophrenic patients suffer from a state of hyperarousal (Venables, 1964), which seems to parallel the heightened response to novelty in APO-SUS rats (see above). There have been several reports of decreased numbers of natural killer cells in schizophrenic patients (DeLisi et al., 1983; Sasaki et al., 1994). We have recently also found decreased numbers of NK cells in APO-SUS rats (A. R. Cools, C. Heynen, A. Kavelaars, and B. A. Ellenbroek, unpublished data). A very interesting finding is the reduced sensitivity of APOSUS rats for rheumatoid arthritis (vandeLangerijt et al., 1994). This agrees very well with the known negative association between rheumatoid arthritis and schizophrenia (Vinogradov et al., 1991).

\section{Overall conclusions}

The results of the present set of experiments showed that rats with an enhanced sensitivity to apomorphinc showed deficits in information processing also seen in several psychomotor diseases, especially schizophrenia. Thus, irrespective of selection procedure (open field, gnawing cage, or pharmacogenetic selection) rats with a high susceptibility to apomorphine showed a decreased prepulse inhibition of the acoustic startle response (especially with weak prepulses) and a diminished latent inhibition, although the strongest effects were seen in the pharmacogenetically selected group. However, the data also suggest that the changes in prepulse inhibition in APO-SUS rats are not as strong as those seen in schizophrenic patients. This suggests that APOSUS rats may represent an interesting model for psychosis-prone (or schizophrenia-prone) patients, especially since these rats show several other (biochemical, endocrinological, and immunological) features also reported for schizophrenic patients.

The present findings of distinct changes in prepulse inhibition and latent inhibition in rats that have never been treated with a drug also may have implications for possible new approaches to the identification of antipsychotic drugs. Most screening tests for antipsychotic treatments rely upon drugs such as dopamine agonists to induce the behavioral deficit of interest. The ability to study the effects of putative antipsychotics in a nonpharmacological behavioual model may help to identify antipsychotic drugs with a novel mechanism of action. In contrast to the cffectiveness of antipsychotics in latent inhibition (Dunn et al., 1993), relatively few studies have found antipsychotics to improve prepulse inhibition in normal rats (Hoffman et al., 1993; Swerdlow and Geyer, 1993). Based on the present results, one would predict that the APO-SUS rats would be more sensitive to the facilitatory effects of antipsychotics on prepulse inhibition.

\section{References}

Baruch I, Hemsley DR, Gray JS (1988) Differential performance of acute and chronic schizophrenics in a latent inhibition task. J Nerv Ment Dis 176:598-606.

Braff DL (1993) Information processing and attention dysfunctions in schizophrenia. Schizophr Bull 18:233-259.

Braff DL, Geyer MA (1990) Sensorimotor gating and schizophrenia: human and animal model studies. Arch Gen Psychiatry 47:181-188.

Cadenhead KS, Geyer MA, Braff DL (1993) Impaired startle prepulse inhibition and habituation in patients with schizotypal personality disorder. Am J Psychiatry 150:1862-1867.

Commissaris RL, Harrington GM, Baginski TJ, Altman HJ (1988) MR/ HAR and MNRA/HAR Maudsley rat strains: differences in acoustic startle habituation. Behav Genet 18:663-669.

Cools AR, Brachten R, Heeren D, Willemen A, Ellenbroek B (1990) Search after the neurobiological profile of individual-specific features of Wistar rats. Brain Res Bull 24:49-69.

Cools AR, Rots NY, Ellenbroek B, deKloet ER (1993) Bimodal shape of individual variation in behavior of Wistar rats: the overall outcome of a fundamentally different make-up and reactivity of the brain, the endocrinological and the immunological system. Neuropsychobiology 28:100-105.

Cools, AR, Rots NY, DeKloet R, Ellenbroek B (1994) Apomorphinesusceptible and apomorphine-unsusceptible Wistar rats: a new tool in the search for the function of the striatum in switching behavioural strategies. In: The basal ganglia IV (Percheron G, McKenzie JS, Feger J, eds), pp 507-515. New York: Plenum.

DeLaCasa LG, Ruiz G, Lubow RE (1993) Latent inhibition and recall/ recognition of irrelevant stimuli as a function of preexposure duration in high and low psychotic prone normal subjects. Br J Psychol 84: 119-132.

DeLisi LE, Ortaldo JR, Maluish AE, Wyatt-RJ (1983) Deficient natural killer cell (NK) activity and macrophage functioning in schizophrenic patients. J Neural Transm 58: 99-106.

Dunn LA, Atwater GE, Kilts CD (1993) Effects of antipsychotic drugs on latent inhibition: sensitivity and specificity of an animal behavioural model of clinical drug action. Psychopharmacology (Berlin) $112: 315-323$

Early TS, Reiman EM, Raichle ME, Spitznagel EL (1987) Left globus pallidus abnormality in never-medicated patients with schizophrenia. Proc Natl Acad Sci USA 84:561-563.

Ellenbroek BA (1993) Treatment of schizophrenia: a clinical and preclinical evaluation of neuroleptic drugs. Pharmacol Ther $57: 1-78$.

Ellenbroek BA, Cools AR (1990) Animal models with construct validity for schizophrenia. Behav Pharmacol 1:469-490. 
Ellenbroek BA, Cools AR (1995) Maternal separation reduces latent inhibition in the conditioned taste aversion paradigm. Neurosci Res Commun 17:27-33.

Farde L, Wiesel FA, Stone-Elander S, Halldin C, Nordstrom AL, Hall $H$, Sedvall G (1990) D2-dopamine receptors in neuroleptic-naive schizophrenic patients. Arch Gen Psychiatry 47:213-219.

Geyer MA, Markou A (1995) Animal models of psychiatric disorders. In: Psychopharmacology: fourth generation of progress (Bloom FE, Kupfer DJ, eds), pp 787-798. New York: Raven.

Geyer MA, Wilkinson LS, Humby T, Robbins TW (1993) Isolation rearing of rats produces a deficit in prepulse inhibition of acoustic startle similar to that in schizophrenia. Biol Psychiatry 34:361-372.

Glowa JR, Hansen CT (1992) Different response to an acoustic startle stimulus among forty-six rat strains. Behav Genet 24:79-84.

Gray NS, Pickering AD, Hemsley DR, Dawling S, Gray JA (1992) Abolition of latent inhibition by a single $5 \mathrm{mg}$ dose of $d$-amphetamine in man. Psychopharmacology (Berlin) 107:425-430.

Grillon C, Ameli R, Charney DS, Krystal J, Braff DL (1992) Startle gating deficit occur across prepulse intensities in schizophrenic patients. Biol Psychiatry 32:939-943.

Hoffman DC, Donovan H, Cassella JV (1993) The effects of haloperidol and clozapine on the disruption of sensorimotor gating induced by the noncompetitive glutamate antagonist MK-801. Psychopharmacology (Berlin) 111:339-344

Killcross AS, Robbins TW (1993) Differential effects of intra-accumbens and systemic amphetamine on latent inhibition using an onbaseline, within-subjects conditioned suppression paradigm. Psychopharmacology (Berlin) 110:479-489.

Mansbach R, Geyer MA, Braff DL (1988) Dopaminergic stimulation disrupts sensorimotor gating in the rat. Psychopharmacology (Berlin) 94:507-514.

Markou A, Matthews K, Geyer MA, Overstreet DH, Koob GF (1993) An investigation of startle reactivity, prepulse inhibition and habituation in Flinders sensitive hyper-cholinergic and Flinders resistant rats. Soc Neurosci Abstr 19:1244.

Martinot JL, Peron-Magnan P, Huret JD, Mazoyer B, Baron JC, Boulenger JP, Loc'h C, Maziere B, Caillard V, Loo H (1990) Striatal D2 dopaminergic receptors assessed with positron emission tomography and ${ }^{76} \mathrm{Br}$-bromospiperone in untreated schizophrenic patients. Am J Psychiatry 147:44-50.

McGhie A (1970) Attention and perception. Prog Exp Pers Res 5:125

Rots NY, Oitzl M, Berod A, Rostene W, Cools AR, deKloet ER (1993) Rat lines genetically selected for differential responsiveness of the dopaminergic system display distinctly different pituitary-adrenal characteristics. Soc Neurosci Abstr 19:942.

Rots NY, Cools AR, deJong J, deKloet ER (1995) Corticosteroid feedback resistance in rats genetically selected for increased dopamine responsiveness. J Neuroendocrinol 7:153-161.

Sasaki T, Nanko S, Fukuda R, Kawate T, Kunugi H, Kazamatsuri H,
(1994) Changes of immunological functions after acute exacerbation in schizophrenia. Biol Psychiatry 35:173-178.

Schwarzkopf SB, Mitra T, Bruno JP (1992) Sensory gating in rats depleted of dopamine as neonates: potential relevance to findings in schizophrenic patients. Biol Psychiatry 31:759-773.

Servatius RJ, Ottenweller JE, Bergen MT, Soldan S, Natelson BH (1994) Persistent stress-induced sensitization of adrenocortical and startle response. Physiol Behav 56:945-954.

Solomon PR, Statton DM (1982) Differential effects of microinjections of $d$-amphetamine into the nucleus accumbens or the caudate putamen on the rat's ability to ignore an irrelevant stimulus. Biol Psychiatry 17:743-756

Swerdlow NR, Geyer MA (1993) Clozapine and haloperidol in an animal model of sensorimotor gating deficits in schizophrenia. Pharmacol Biochem Behav 44:741-744.

Swerdlow NR, Masten VL, Braff DL, Geyer MA (1990) Schizophrenic-like sensorimotor gating abnormalities in rats following dopamine infusion into the nucleus accumbens. Psychopharmacology (Berlin) 101:414-420.

Swerdlow NR, Benbow C, Zisook S, Geyer MA, Braff DL (1993) A preliminary assessment of sensorimotor gating in patients with obsessive compulsive disorder. Biol Psychiatry 33:298-301.

Toru M, Shibuya $H$, Mitsushio $H$, Noda $K$, Nishikawa T, Ichikawa $H$, Takashima M, Mataga M, Watanabe S (1984) Biochemical analysis of neurotransmitters and neuropeptides in post-mortem schizophrenic brains. Coll Int Neuropsychopharmacol Abstr Book p. 10

VandeLangerijt AGM, vanLent PLEM, Hermus ARMM, Sweep CGJ Cools AR, vanden Berg WB (1994) Susceptibility to adjuvans arthritis: relative importance of adrenal activity and bacterial flora. Clin Exp Immunol 97:33-38.

Venables PH (1964) Input dysfunction in schizophrenia. Prog Exp Pers Res 1:1-47.

Vinogradov S, Gottesman II, Moises HW, Nichol S (1991) Negative association between schizophrenia and rheumatoid arthritis. Schizophr Bull 17:669-678.

Wan FJ, Geyer MA, Swerdlow NR (1994) Accumbens D2 modulation of sensorimotor gating in rats: assessing anatomical localization. Phanmacol Biochem Behav 49:155-163.

Weiner I, Lubow, RE, Feldon J (1984) Abolition of the expression but not acquisition of latent inhibition by chronic amphetamine. Psychopharmacology (Berlin) 83:194-199.

Wilkinson LS, Killcross AS, Humby T, Hall FS, Torres EM, Geyer MA Robbins TW (1994) Social isolation produces developmentally specitic deficits in prepulse inhibition of the acoustic startle response but does not disrupt latent inhibition. Neuropsychopharmacology 10:6172.

Willner P (1984) The validity of animal models of depression. Psychopharmacology (Berlin) 83:1-16.

Wong D, Wagner H, Tune L, Dannals R, Pearlson G, Luinks J, Tamminga $\mathrm{C}$, Brousolle E, Ravert $\mathrm{H}$, Wilson A, Toung J, Malta J, Williams J, O'Tuama L, Snyder S, Kuhar M, Gjedde A (1986) Positron emission tomography reveals elevated $D_{2}$ dopamine receptors in drug-naive schizophrenics. Science 234:1558-1563. 